\title{
Functionalised type-I collagen as a hydrogel building block for bio-orthogonal tissue engineering applications
}

\author{
Ranjithkumar Ravichandran, M. M. Islam, E. I. Alarcon, A. Samanta, S. Wang, \\ Patrik Lundström, J. Hilborn, May Griffith and Jaywant Phopase
}

\section{Linköping University Post Print}

\section{Tweet}

N.B.: When citing this work, cite the original article.

Original Publication:

Ranjithkumar Ravichandran, M. M. Islam, E. I. Alarcon, A. Samanta, S. Wang, Patrik Lundström, J. Hilborn, May Griffith and Jaywant Phopase, Functionalised type-I collagen as a hydrogel building block for bio-orthogonal tissue engineering applications, 2016, Journal of materials chemistry. B, (4), 2, 318-326.

http://dx.doi.org/10.1039/c5tb02035b

Copyright: Royal Society of Chemistry

http://www.rsc.org/

Postprint available at: Linköping University Electronic Press

http://urn.kb.se/resolve?urn=urn:nbn:se:liu:diva-124491 


\section{Journal Name}

\section{ARTICLE}

\section{Functionalised type-I collagen as hydrogel building block for bio- orthogonal tissue engineering applications.}

Received 00th January 20xx, Accepted 00th January 20xx www.rsc.org/

\begin{abstract}
R. Ravichandran, ${ }^{a, \S}$ M.M. Islam, ${ }^{b, \S}$ E. I. Alarcon, ${ }^{c}$ A. Samanta, ${ }^{d}$ S. Wang, ${ }^{e}$ P. Lundström, ${ }^{f} J$. Hilborn, ${ }^{e}$ M. Griffith, ${ }^{d^{*}}$ and J. Phopase ${ }^{a^{*}, \dagger}$

In this study, we derivatized type I collagen without altering its triple helical conformation to allow for facile hydroge formation via Micheal addition of thiols to methacrylates without the addition of other crosslinking agents. This method provides the flexibility needed for fabrication of injectable hydrogels or pre-fabricated implantable scaffolds, using the same components by tuning the modulus from $\mathrm{Pa}$ to $\mathrm{kPa}$. Enzymatic degradability of the hydrogels can be also easily fine tuned by variation of the ratio and type of cross-linking component. The structural morphology reveals lamellar structure mimicking native collagen fibrils. The versatility of this material is demonstrated by its use as a pre-fabricated substrate for culturing human corneal epithelial cells, and as an injectable hydrogel for 3-D encapsulation of cardiac progenitor cells.
\end{abstract}

Keywords: bio-orthogonal chemistry, tissue engineering, pre-fabricated scaffolds, injectable scaffolds, cell compatible.

\section{Introduction}

The extracellular matrix (ECM) provides mechanical support as well as instructive signals for cell development, migration, proliferation, survival and function. Natural biopolymers derived from the ECM are therefore by nature, very biocompatible and bio-interactive. ${ }^{1-3}$ The most abundant is collagen that has extensively been used to prepare scaffolds for tissue repair and engineering. This structural ECM component has, however limited number of functional groups that can be used for direct crosslinking. ${ }^{4}{ }^{5}$ The main functional groups are amine and carboxylic acids, which allows collagen to crosslinked (e.g. via UV, thermal heating, carbodiimides, epoxy or aldehyde crosslinkers).

Conversely, synthetic polymers such as poly (ethylene) glycols, poly (lactic acids), poly (methacryl/acryl amides)

a.Integrative Regenerative Medicine Centre (IGEN) and Division of Molecula Physics, Department of Physics, Chemistry and Biology (IFM),Linköping University, S-58183, Linköping, Sweden.

b.Integrative Regenerative Medicine Centre (IGEN) and Swedish Medica Nanoscience Center, Department of Neurosciences, Karolinska Institutet, S-17177, Stockholm, Sweden.

Division of cardiac surgery research, University of Ottawa Heart Institute, Ottawa, ON, Canada and Department of Biochemistry, Microbiology and Immunology, Faculty of Medicine, Ottawa, ON, Canada.

d.Integrative Regenerative Medicine Centre and Department of Clinical and Experimental Medicine (IKE), Linköping University, S-58185, Linköping, Sweden.

e.Polymer Chemistry Division, Department of Chemistry, Ångstrom Laboratory, Uppsala University, Box 538, 75121 Uppsala, Sweden.

f.Division of Chemistry, Department of Physics, Chemistry and Biology (IFM), Linköping University, S-58183, Linköping, Sweden.

$\S^{*}$ Equivalent Contributions

+Correspondence to: Jaywant.Phopase@liu.se

ףElectronic Supplementary Information (ESI) available: Synthesis of methacrylated collagen details and characterization after modification, including the fabrication of thiol-Michael hydrogels by varying the concentration of crosslinkers; details about structural elucidation, gelation time and mechanical properties measurement of hydrogels, details about enzymatic degradation, in vitro cell seeding and cell encapsulation on the hydrogel matrix. See DOI: 10.1039/x0xx00000x etc.), are easily chemically modified for facile processing than collagen. ${ }^{6}$ However, synthetic polymers have issues with biocompatibility, degradability and do not completely integrate within the host. ${ }^{7-9}$ Hence, synthetic routes to introduce biocompatible crosslinkable modifications on the protein structure, (reactive moieties), are highly desirable for the development of the next generation of regenerative materials for tissue engineering. Particularly, introducing reactive moieties in collagen would expand its functionality allowing for development of a wider range of scaffolds that can serve as regeneration templates. ${ }^{10,11}$

Several routes to render collagen more processable while retaining its in vitro/ in vivo or clinical bio interactive capacity for promoting tissue regeneration have been explored. ${ }^{12-14}$ The simplest method is blending collagen with natural or synthetic polymers (such as hyaluronic acid, chitosan, poly(ethylene oxide), polylactic acid, and polyglycolic acid) to fabricate scaffolds. ${ }^{5}, 15$ Crosslinked collagen-chitosan hydrogels, which were mechanically stronger than collagen alone, promoted angiogenesis and has been used for islet transplantations in murine models. ${ }^{16} \mathrm{Li}$ et al. co-polymerized collagen with laminin-peptide functionalized poly( $\mathrm{N}^{\prime}$-isopropylacrylamide) (PNIPAAm) to form a corneal implant. When tested in mini-pig eyes, these hybrid biomaterials promoted regeneration of corneal and neural tissues. ${ }^{16}$ Another technique is the fabrication of interpenetrating networks of biomaterials using gold standard EDC-NHS coupling. Our team had developed a carbodiimide crosslinked recombinant human collagen network that was reinforced with a network of synthetic phosphorylcholinepoly(ethylene glycol) diacrylate to form an interpenetrating network that were subsequently moulded into corneal implants. These have now been grafted into 3 patients with 

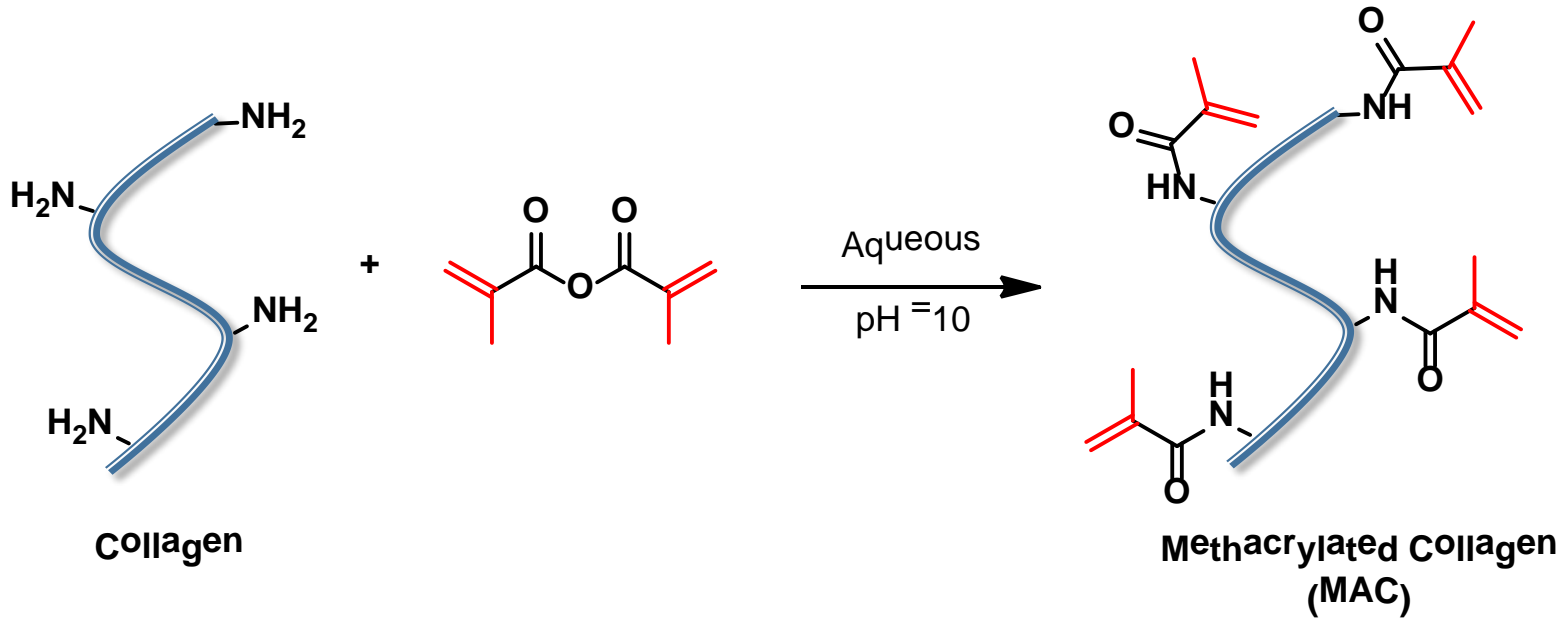

Fig. 1 Synthesis of Methacrylated Collagen (MAC)

high risks for rejection of conventionally transplanted human donor cornea. ${ }^{17}$

In many instances, traditional chemical crosslinking techniques result in superior thermal and mechanical properties in comparison to physical crosslinking techniques. However, they tend to suffer from toxicity issues. For example, in crosslinking of collagen or other ECM proteins with carbodiimides, unreacted residues or secondary products such as urea that is formed, are cytotoxic. ${ }^{12}$ The use of aldehyde crosslinkers has cytotoxic implications both in vitro and in vivo during degradation of implants, as the aldehydes are released locally. ${ }^{18-20}$

Although there are some reports available about thiol-ene based bioactive hydrogels derived from synthetic and biological sources ${ }^{21,22}$ the objectives of our present study were two-fold - to functionalize collagen without altering the native structure and bioactivity of collagen; and to circumvent the risk of cytotoxicity by using cell-friendly crosslinking strategies. We first functionalized collagen type I by methacrylation under aqueous conditions without changing its tertiary structure and its ability to interact with cells. We then reacted the functionalized collagen with a PEG-thiol to obtain cell-compatible hydrogels with tunable properties. The resulting hydrogels were characterized and their functional versatility was evaluated in two model tissue-engineering applications, as solid substrates for proliferation and delivery of corneal epithelial cells and injectable hydrogels as a delivery vehicle for cardiac stem cells.

\section{Results and discussion}

\section{Functionalisation of Collagen}

Although the modification of collagen $^{23}$, and other biomolecules like gelatin, ${ }^{19,}{ }^{20}$ hyaluronic acid, alginate, ${ }^{4,} 24$ elastin, ${ }^{25}$ dextran, ${ }^{26}$ chitosan $^{27}$, using methacrylate functional groups has been reported in the literature, the degree of modification achieved was low and the potential of methacrylated collagen(MAC) as a functional building block to create multi-functional scaffolds has not been explored. ${ }^{28}$
With our synthetic procedure the amine functionality on the lysine residue undergoes nucleophilic substitution with methacrylic anhydride (MAA) in aqueous medium with no additional organic solvents to attain high degree of modification ( $\sim 85 \%)$ using very low molar concentration of reactants (Fig. 1 and 2). The higher degree of modification at a relatively low molar concentration of reactant (MAA) was achieved by de-protonation of amine groups at a basic $\mathrm{pH}$ that in turn promotes rapid nucleophilic attack of the amine groups of collagen onto anhydride linkage on MAA. The extent of modification of collagen after methacrylation was determined using the TNBS (2,4,6-trinitrobenzene sulfonic acid) colorimetric assay and NMR spectroscopy (Fig. 2). TNBS solution was mixed with functionalized and nonfunctionalized collagen using protocol described earlier ${ }^{29}$ to assess the non-functionalized free amine groups. TNBS reagent reacts with free lysine amines and forms a chromogenic TNP derivative that has an absorbance at 346nm, (Fig. 2 left). The intensity of MAC at 346nm decreased after modification and the degree of functionalization (F) has been found to be $85-87 \%$ (at a $1: 5$ molar ratio of lysine amines: MAA) calculated from (equation 1 and 2 see ESI 9 ). Varying the molar ratios (1: 1.5; lysine amines: MAA) resulted in altered degree of functionalization (F, 57-60\%). Further characterization using ${ }^{1} \mathrm{H}-\mathrm{NMR}$ spectroscopy for functionalized collagen (Fig. 2 right) displayed the presence of peaks between $\delta=5.3$ and $5.5 \mathrm{ppm}$ characteristic for the double bonds of acrylic protons of methacrylamides. In addition a signal at $\delta=1.8 \mathrm{ppm}$ corresponds to the methyl group of methacrylate. The signal at $\delta=2.89 \mathrm{ppm}$ was assigned to methylene hydrogen of lysine amines that was used as a reference signal to quantify the degree of modification. The degree of functionalization as gauged by NMR analysis was $79-81 \%$ of the available amine functionalities (see equation 3 experimental section, ESI $)$ ), which is in close agreement with the quantification obtained from TNBS assay. 

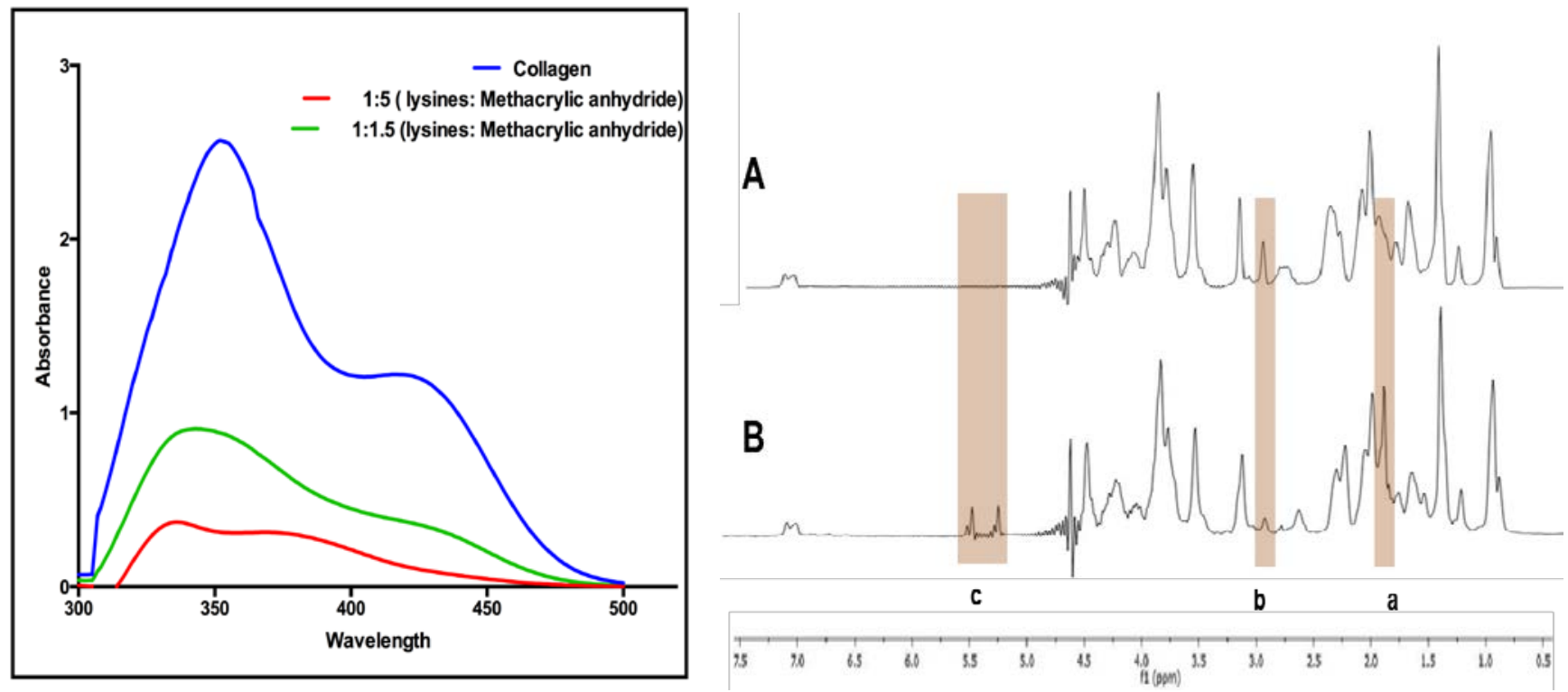

Fig. 2 Characterization of functionalized collagen using UV-Vis spectroscopy (Left) UV-Vis absorption spectra for pristine collagen and MAC resulted from TNBS assay. All measurements were carried out at room temperature in a $1 \mathrm{~cm}$ cuvette. (Right) ${ }^{1} \mathrm{H}$ Nuclear Magnetic Resonance (NMR) spectrum of pristine collagen (A) and MAC (B). The methyl signal of methacrylate (a) lysine methylene signal (b) and signals of olefinic protons from methacrylate (c) indicates the modification of collagen.

From the UV absorption spectra and NMR studies it is evident that collagen had been functionalized with methacrylate groups. Further, the flexibility to predictably alter the degree of functionalization by varying the reactant molar ratio provides the potential to control and manipulate the properties of resultant scaffold and can serve as an important tool for designing tailor specific scaffolds.

\section{Structural elucidation of methacrylated collagen (MAC)}

Collagen is characterized by the presence of its unique triple helical structure. In native ECM, the triple helicity contributes to the mechanical strength of collagen as a structural material. However, the triple helicity also confers other biological activities and interacts with other biomolecules to create a microenvironment to direct cell behaviors. ${ }^{18,} 19$ These functions are important to promote tissue regeneration and therefore it is significant to retain the triple helical integrity of collagen after modification. Gelatin, a denatured form of collagen does not have the same triple helical integrity and crosslinked gelatin scaffolds possess lower mechanical properties than collagen derived scaffolds that highlight the importance of collagen in tissue engineering applications. ${ }^{30,31}$ The structural integrity of functionalized collagen was verified using circular dichroism analysis. CD spectra analysis of unmodified collagen resulted in the positive maximum absorption at $221 \mathrm{~nm}$ and negative absorption at 180-190nm with a Ratio of Positive to Negative Peak (Rpn) value closer to 0.12 implying the characteristic triple helical structure of collagen. Organic solvents and temperatures easily denature collagen, requiring chemical reaction in water or mild organic solvents to maintain the physiological stability and preserve the native structure of protein. The measured CD spectrum of MAC resulted in similar spectra to that of native collagen spectra with an Rpn value of 0.13 indicating the retention of the triple helical assembly after $>85 \%$ modification of collagen's lysines. ${ }^{32,} 33$ Sameness in Rpn values after methacrylate modification indicates the specific functionalization of collagen at $\varepsilon$ amines of lysine that did not alter the triple helical propensity. From our CD spectroscopic analysis it is evident that the intrinsic structure of collagen was largely retained after modification (Fig. 3).

\section{Construction of covalently cross-linked hydrogels using bio-orthogonal thiol-Michael Addition Click Reaction with tuneable gelation}

Methacrylated collagen (MAC) was further used as a building block to fabricate tailor-made scaffolds using thiol-Michael addition click chemistry. The fabrication of hydrogels using MAC and multi-arm thiols are described in experimental section at ESI and illustrated in Fig. 4. One of the major factors that dictate the design of hydrogels tailored towards specific biomedical applications (such as cell encapsulation or loading of drugs) depends on the gelation time. The gels with shorter gelation time can serve to encapsulate cells inside the matrix and can be used as injectable scaffold for target specific applications. ${ }^{34,}{ }^{35}$ It is well known in literature that gelation time is dependent on the PEG's molecular architecture; that 4arm PEGs have shorter gelation time than 8armPEGs. ${ }^{36}$ 


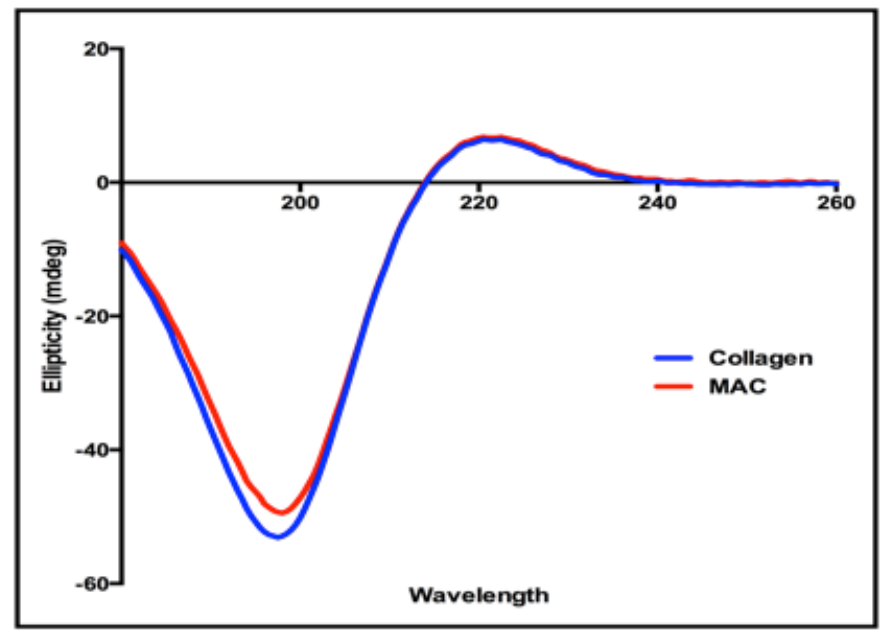

Fig. $3 \mathrm{CD}$ spectrum of pristine collagen and MAC. An identical spectrum of collagen and MAC indicates the retention of triple helix after modification. All measurements were carried out at room temperature in a $0.1 \mathrm{~cm}$ cuvette.

Our observations were also similar and we demonstrated the in vitro prospects of it in our subsequent sections. The stiffness and gelation time of the formulation depends on the number functional components in it and can be customized by adjusting the crosslinker concentration and $\mathrm{pH} .^{18,19,37}$

The rate of the crosslinking reaction between the modular sub-units to form the final product is $\mathrm{pH}$ dependent and it was evaluated using in situ rheological analysis shown in Fig. S1 and S2 of the ESI ${ }^{38,} 39$ Adjustment of $\mathrm{pH}(\approx 8-8.2)$, generated thiolate anions and promoted faster nucleophilic attack on MAC to form stable hydrogels in short tenure compared to formulations without the catalyst ( $\mathrm{pH} 6.6 \approx 6-8){ }^{34-}$ 35,40 Fig. S1A depicts the in situ gelation kinetics of 4 arm PEG thiol with and without catalyst Triethanolamine (TEOA) (M4A2 and M4A2.1 formulations). Addition of 0.05M TEOA to the formulation accelerated the gelation at room temperature to generate crosslinked hydrogel in 2.5-3h subsequently longer gelation time $>8$ hours had been observed without the addition of catalyst. At basic $\mathrm{pH}$ the electrostatic attraction between the intermolecular collagen fibrils increases along with acceleration of gelation yielding in higher stiffness of the hydrogels ${ }^{35}$ therefore TEOA was added as a catalyst to all the formulations to evaluate mechanical properties that has been discussed in next section. Likewise, we have also modified the collagen with acrylates and compared the in situ gelation kinetics of acrylated collagen (AC) versus MAC. Acrylates have higher reactivity than methacrylates due to inductive effect of alkyl substituent in methacrylate. ${ }^{41}$ We have also observed the same sigmoidal trend, where the acrylates with TEOA (A4A2 fromulation) took $2.5 \mathrm{~h}$ to attain complete crosslinking (Fig. S1B at ESI ף). $\mathrm{AC}$ has shorter gelation time at different $\mathrm{pH}$ conditions compared to methacrylated collagen thereby providing the flexibility to use suitable building block for specific needs. More interestingly, without the addition of catalyst to AC (A4A2.1 formulation) took merely $4-5 \mathrm{~h}$ to crosslink to form final hydrogel product whereas MAC took more than $8 \mathrm{~h}$. The material properties of AC hydrogels will be brought into fore in our succeeding manuscript.

Fig. S2 at ESI ๆ illustrates the gelation kinetics of 8 arm PEG thiol (M8A3 and A8A3 formulations) with 0.05M TEOA addition on both MAC and AC formulations. We observed similar sigmoidal gelation trend like 4 arm formulations but the reaction rate even in the presence of catalyst was slightly slower. Addition of catalyst to both MAC and AC formulations (M8A3 and A8A3) resulted in shorter gelation time (2.5-3 h) to form 70-75\% of hydrogel product and took 6 hours to attain complete crosslinking. In case of AC, though the initial rate of the reaction was slightly higher than MAC, the gelation time was similar to MAC. Without catalyst it took more than $10 \mathrm{~h}$ to complete the gelation for both MAC and AC (data not shown).

\section{Structural and Mechanical properties of hydrogels}

The mechanical properties of different tissue under physiological conditions are dissimilar, so information about the mechanical properties of biomaterials are important to investigate to design tissue scaffolds for specific targeted tissues or organs, from soft tissue like brain, nerves etc. $\left(10^{2}-\right.$ $\left.10^{3} \mathrm{~Pa}\right)$ to hard tissue like connective tissue, bone $\left(10^{6}-10^{8}\right.$ $\mathrm{Pa}){ }^{42}{ }^{43}$ Increasing the functional equivalents of multiarm PEG thiols (8A and 4A) with respect to MAC tailored the mechanical properties from soft to ten times stiffer hydrogels that were evaluated using rheological analysis (Fig. 5 and Table 1). The $\mathrm{G}^{\prime}$ value increased from $10 \mathrm{kPa}$ to $100 \mathrm{kPa}$ for 8 arm thiol formulations and $15 \mathrm{kPa}$ to $90 \mathrm{kPa}$ for 4 arm thiol formulations. The frequency dependent measurements of our hydrogels from all formulations showed that the storage modulus $\left(G^{\prime}\right)$ was always higher than the loss modulus $\left(G^{\prime \prime}\right)$ showing that the hydrogels are predominantly elastic. Several reports had explored the major factors affecting hydrogel mechanical properties ${ }^{44}, 45$ including concentration of components, crosslinking density, molecular weight ${ }^{38}$ that supports our strategy to easily modulate the stiffness of hydrogel by (1) varying the final concentration of MAC, (2) varying the degree of collagen modification, (3) varying the molecular weight and molecular architecture of crosslinking components. Several authors have already shown the parameters influencing the crosslinking density and mechanical properties of hydrogel ${ }^{38,39}$ for e.g. the maximum stiffness reported by crosslinking hyaluronic acid functional groups using thiol-Michael addition click reaction was about $8.2 \mathrm{kPa}$ after $456 \mathrm{~h}$ of post gelation ${ }^{46}$; but we are first to design collagen derived hydrogels with relatively high modulus of $100 \mathrm{kPa}$ using thiol-Michael Addition Click reaction in a very short time (3-4h). Further increase in the thiol concentration does not form a homogenous hydrogel due offset in stoichiometry. Structure-property relationship of crosslinked hydrogels was evaluated by examining the mesh size or correlation length $(\xi)$, which is the average linear distance between two adjacant crosslinks, as well as the average molecular weight between crosslinks (Mc) using equation 6 and 7 (ESI $)$ from rheological analysis. The values of $\xi$ and $\mathrm{Mc}$ for all formulations were listed in Table 1. 
Decrease of $\mathrm{Mc}$ and $\xi$ as a function of crosslinker concentration lead to rising stiffness of hydrogel by aligning the collagen fibrils in close proximity that reflects in optical clarity. ${ }^{39,} 47$ The higher modulus and crosslinking density is also reflected in a higher gel content that for the low modulus gels is $75 \%$ and for the higher modulus gels almost approached $90 \%$. The robust nature of thiol-Michael addition click reaction has unique advantages as compared to traditional coupling strategies offering high bio-orthogonality that involve only thiols and methacrylates/acrylates to form stable thio-ether bonds without forming any side product. ${ }^{48}$ Using this chemistry we can generate the implantable scaffolds to support cell growth, and also could be permissible to fabricate injectable 3D matrices. Cryoscanning electron microscopy (cryo-SEM) imaging of sections through thiol-Michael hydrogels showed that they are comprised with thin lamellae interconnected with fine fibrils. The highly regular structure likely contributed to its optical clarity (Fig. 6A). The enzymatic degradation profiles of the hydrogels have also been modulated as a function of concentration of reacting components (Fig. 6B). The alteration in stiffness due to crosslinking density also alters the pore size and enzymatic degradation profiles. We have chosen two different formulations of 8A (M8A3 and M8A4) to demonstrate the modulation of structural and enzymatic properties. Similarly the hydrogel (M8A3) with low stiffness also showed higher enzymatic degradation against collagenase, whereas the control hydrogel undergone degradation in 5-8 hours. 90\% of M8A3 gels undergone degradation over a period of 5 days. Subsequently (M8A4) increasing the stiffness it demonstrated higher resistance to collagenase treatment. $50 \%$ of M8A4 gels remained stable against collagenase over a period of 5 days.

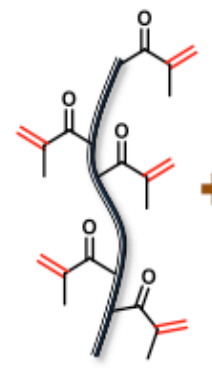

Methacrylated Collagen (MAC)

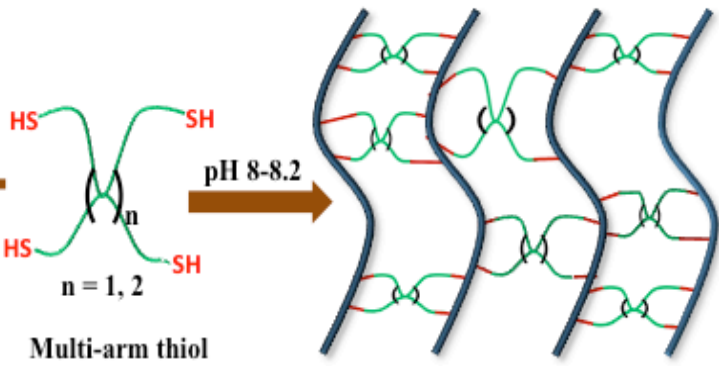

Tunable mechanical structural and enzymatic properties

Bond between thiol and methacrylate
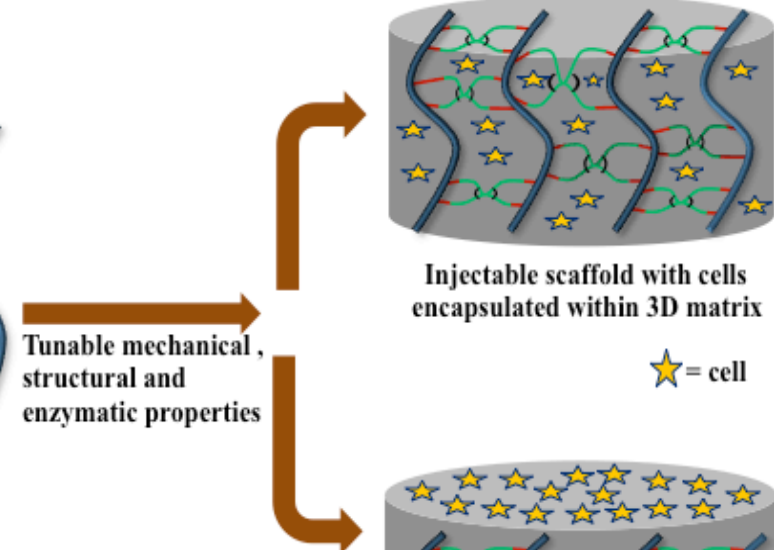

Injectable scaffold with cells encapsulated within 3D matrix

$\hat{\mathrm{w}}=$ cell

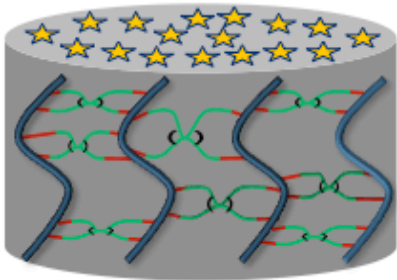

Implantable self supporting scaffold with cells seeded on the top

Fig. 4 Fabrication of Michael-thiol (MT) hydrogel by covalently crosslinking of MAC and multi-arm PEG thiols (4 and 8-arm) via thiol-Michael addition click reaction. PEG thiols acts as crosslinkers that reacts with methacrylic groups in collagen that allows the formation of multiple covalent bonds between polymeric chain and collagen to form hydrogel. Gelation time, mechanical, structural and enzymatic properties can be significantly altered rendering them to use is as implantable scaffolds as well as injectable 3D biomatrix to encapsulate viable cells for target specific delivery. 


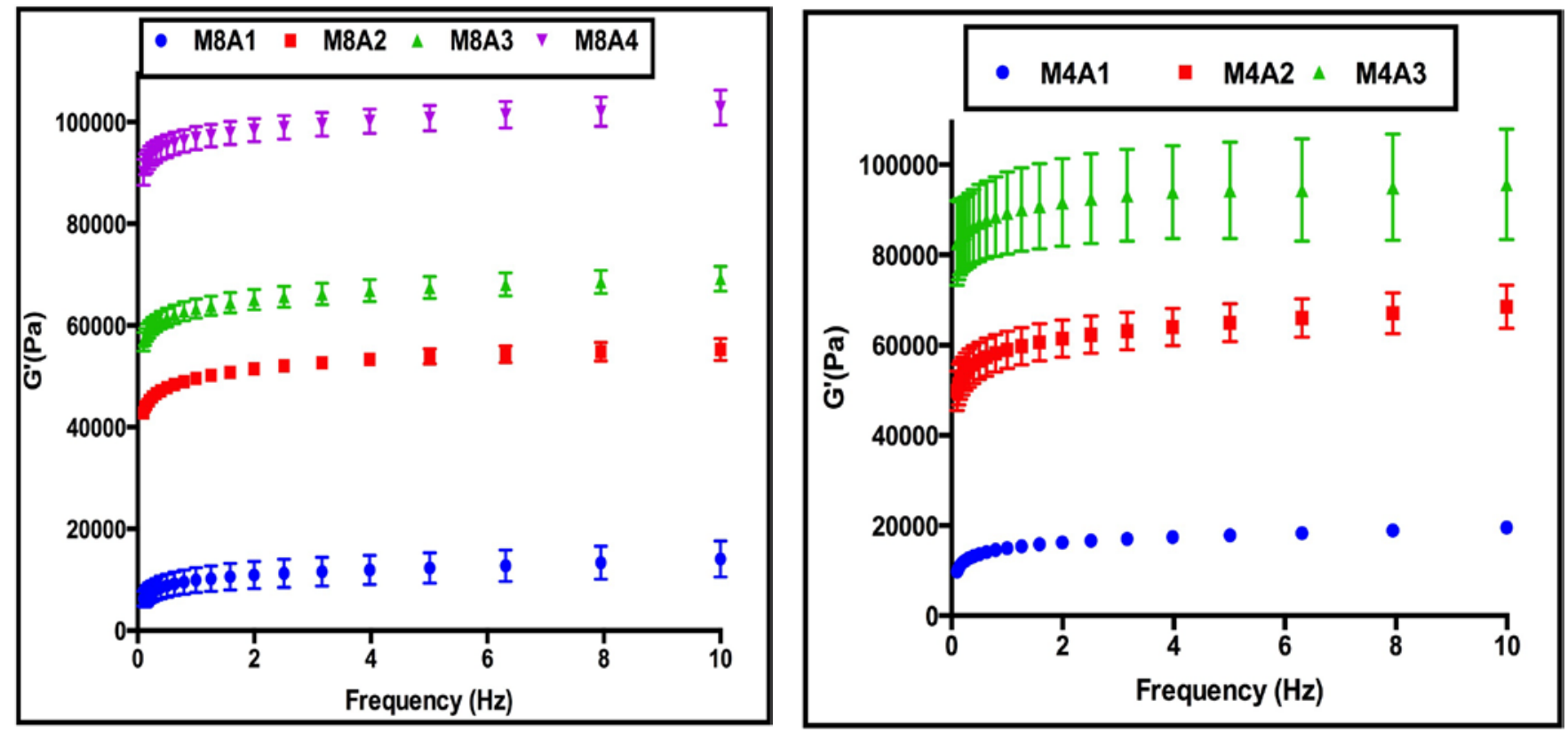

Fig. 5 Rheology graphs of PEG 8 arm (A) and 4 arm (B) thiols cross-linked with methacrylated collagen at different functional ratios.
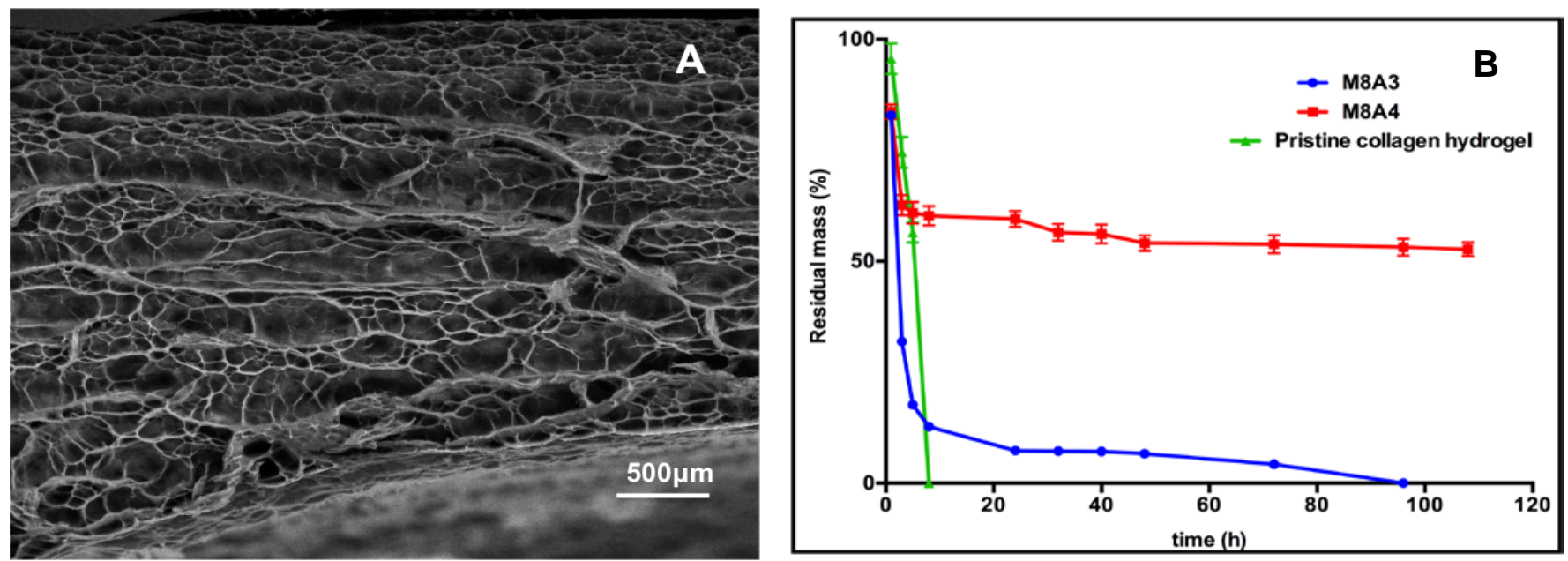

Fig. 6 (A) Scanning electron micrographs showing an example of thiol-Michael hydrogel (M8A4) with highly regular lamellae with fine interconnecting fibrils Scale bar $=500 \mu \mathrm{m}$; (B) Degradation profiles of Pristine collagen hydrogel (fabrication mentioned in materials section ESI $)$ ), M8A3 and M8A4 thiol-Michael hydrogels after collagenase treatment. After 5 hours no residues were remained in control samples while $90 \%$ of $M 8 A 3$ and $50 \%$ of M8A4 hydrogels remained over 5 days. 


\begin{tabular}{|c|c|c|c|c|c|c|c|}
\hline 8arm & $G^{\prime}(\mathrm{kPa})$ & $G^{\prime \prime}(k P a)$ & $\tan (\delta)$ & $\xi(\mathrm{nm})$ & $\begin{array}{c}\text { Gel fraction } \\
(\%)\end{array}$ & $\begin{array}{l}\text { Calculated } \\
\text { Mc } \\
\left(\approx \mathrm{g} \mathrm{mol}^{-1}\right)\end{array}$ & $\begin{array}{l}\text { Theoretical } \\
\text { Mc } \\
\left(\approx \mathrm{g} \mathrm{mol}^{-1}\right)\end{array}$ \\
\hline M8A1 & $10 \pm 0.25$ & $1.9 \pm 0.39$ & 0.214 & 8.69 & $72.92 \pm 2.65$ & 1055 & 5200 \\
\hline M8A2 & $49.51 \pm 0.8$ & $4.2 . \pm 0.52$ & 0.084 & 4.58 & $76.60 \pm 2.80$ & 235 & 2700 \\
\hline M8A3 & $63.30 \pm 1.95$ & $3.6 \pm 0.27$ & 0.056 & 4.17 & $80.89 \pm 4.02$ & 186 & 1450 \\
\hline M8A4 & $96.87 \pm 2.39$ & $3.3 . \pm 0.16$ & 0.034 & 3.58 & $88.75 \pm 2.40$ & 124 & 825 \\
\hline
\end{tabular}

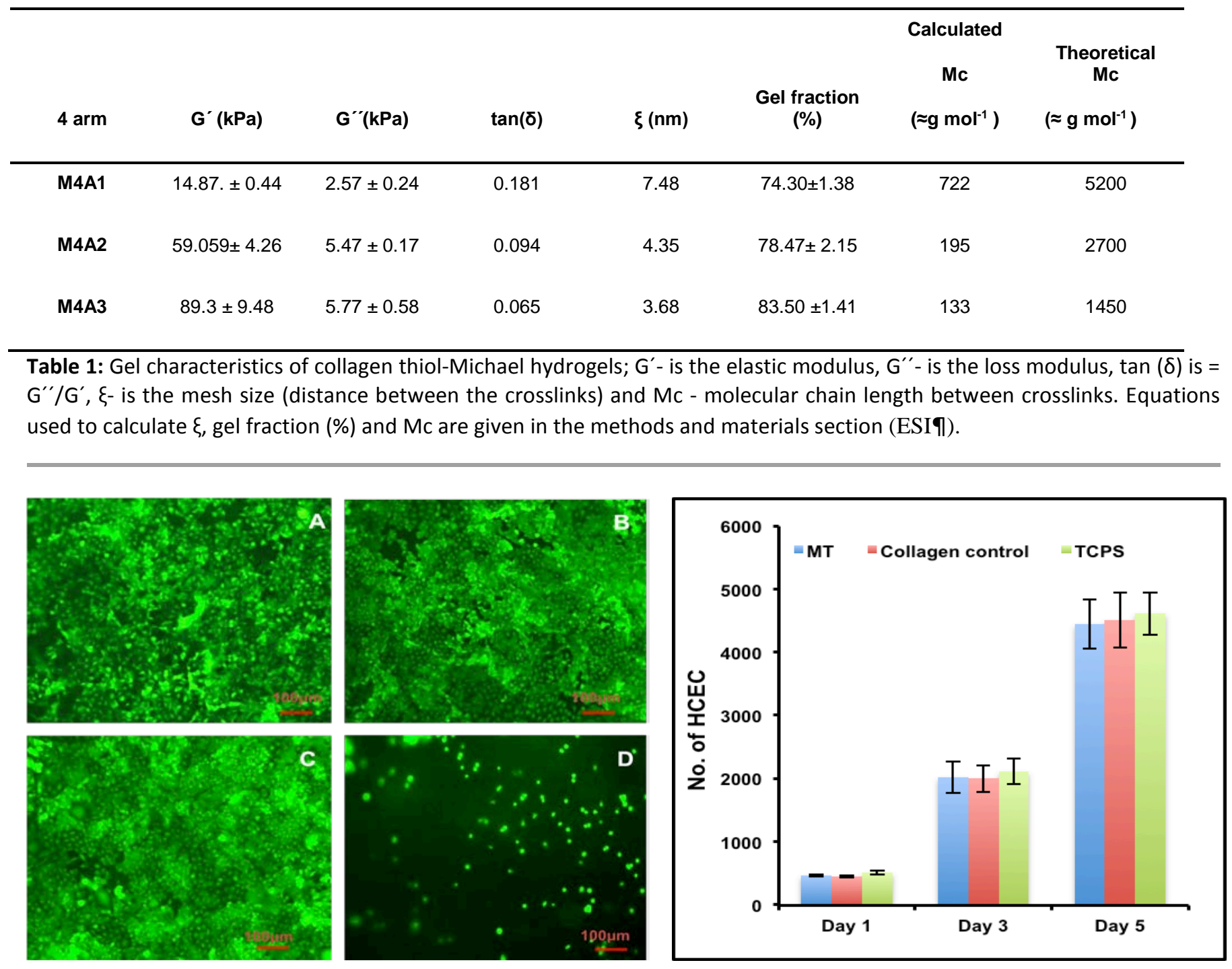

Fig. 7 (I) Fluorescent microscopic images showing the HCEC proliferation on M8A4 thiol-Michael hydrogel surface (A), TCPS (B), pristine collagen hydrogel surface (C) and PEG-SH+PEG-maleimide hydrogel surface (fabrication mentioned at materials section in ESI П.) (D). Scale bars = $100 \mu \mathrm{m}$. (II) Proliferation rates of human corneal epithelial cells on thiol-Michael hydrogel (MT), Control collagen hydrogel and TCPS at days one, three and five of cell culture. Samples were run in triplicate ( $n=3$ ) and repeated for three independent experiments. Results were expressed as average cell counts and the standard deviation. 

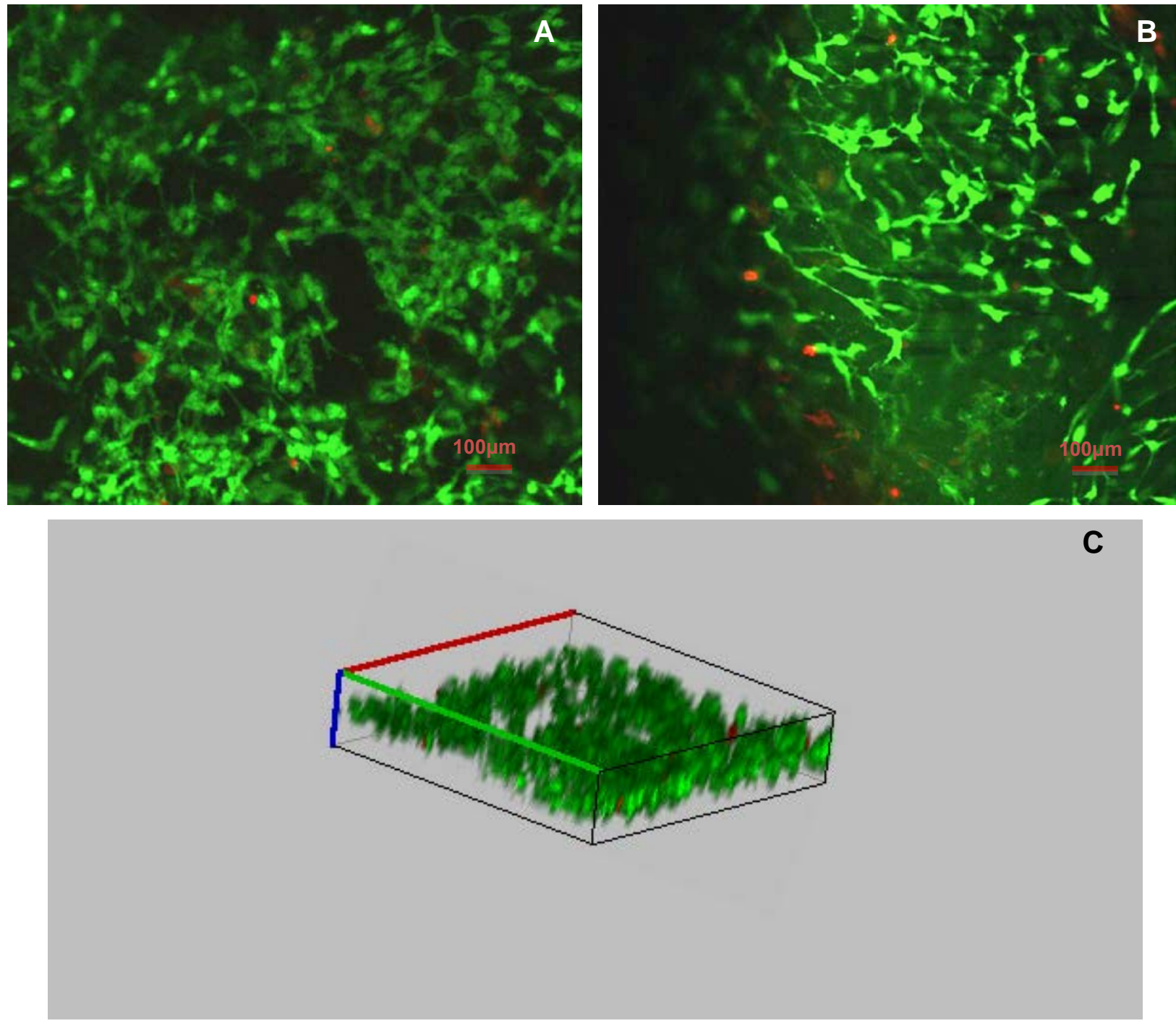

Fig. 8 Confocal laser microscope images of cardiac progenitor cells encapsulated within a Michael- thiol hydrogel (A) and a control collagen thermogel (B). Green cells indicate live cells by Live-Dead staining, while dead cells are red. (C) 3-D distribution of cells within a thiol-Michael hydrogel matrix (C). Scale bars $=100 \mu \mathrm{m}$

\section{Versatility of hydrogels as substrate and for 3-D cell} encapsulation

The versatility of our thiol-Michael hydrogel was tested in two model systems. In the first, human corneal epithelial cells (HCEC) were seeded on top of pre-fabricated stiffer hydrogels (M8A4) and proliferation of HCEC was evaluated. HCECs attachment and proliferation on the MT-hydrogels was observed on Day 1. By Day 5 the cells were confluent in MT hydrogels similar to the Tissue culture polystyrene (TCPS) and pristine EDC-crosslinked collagen hydrogel controls. Quantification of cells to estimate its proliferation was done using FIJI (Image J2) software and the cell count graph has been depicted in Fig. 7. Hydrogels made by crosslinking 8 arm PEG thiol with 8 arm PEG maleimide was used as a negative control to observe the cell attachment and proliferation. The proliferation of cells in the thiol-Michael hydrogels were equivalent to the pristine collagen hydrogel and TCPS but the seeded cells on the negative control failed to attach onto hydrogel surface even after 1 day and undergone apoptosis on long term culture. It has been reported in several studies that stiffer gels promote anchorage dependent cell attachment and spreading and have the ability to withstand the traction forces elicited by the cells. Collagen, being an ECM component has their RGD specific sequence that promotes the adhesion and proliferation of cells on the 
hydrogels. ${ }^{49,50}$ Conversely, the cells remained rounded and underwent apoptosis in our negative control hydrogel fabricated from synthetic polymers. Synthetic polymers lack the focal adhesion points to anchor the cells that resulted in early apoptosis to cells. ${ }^{51}$ The results illustrate the importance of hybrid multicomponent scaffolds comprising of both natural and synthetic components towards tissue engineering / regenerative medicine applications. The materials with high stiffness M8A4 serving as implantable scaffolds can be used as tissue substitute for long-term tissue engineering applications.

Using a faster gelling formulation with low stiffness and mesh size (M4A2), we incorporated murine cardiac progenitor cells (CPCs) into the hydrogel. Viability of the progenitor cells inside the bio-matrix was evaluated using live-dead assay showed that the cells are highly viable inside the matrix after 3 days (Fig. 8). Cell encapsulated hydrogel matrix was incubated with calcein AM and ethidium homodimer dyes for 30 min's to assess the live/dead cells inside the matrix. The encapsulated CPCs were homogenously distributed and remained viable inside the matrix after 3 days of culture and spread, showing its elongated morphology. The thiol-Michael hydrogel matrices biodegraded over a 5day period releasing the CPCs onto tissue culture plates. This shows that the soft hydrogels can potentially be used as a delivery system for injection of CPCs into the heart. It is been known that soft hydrogels are more suitable candidates for cell encapsulation. ${ }^{3}$ Here, varying the degree of methacrylation or modification plays an important role in stiffness of hydrogels that will in turn allow for differential utility of the hydrogels.

The modular fabrication of biomaterials allows the designer to create a series of multi-functional matrices that can be used for multi-tissue engineering applications. ${ }^{52,53}$ Therefore it is highly desirable to have a universal platform for biomaterial development that will allow (1) cell growth and differentiation without added functionalization of the scaffold with bioactive moieties, (2) encapsulation of cells, (3) predictable and straightforward manipulation of biochemical and mechanical properties of the scaffold and (4) fabrication of scaffolds from same polymers suitable as injectable hydrogels for delivering cells to implantable materials, by implementing only minor changes in the fabrication strategy instead of a de novo synthesis., ${ }^{3} 4$ There are several reports available based on the covalent crosslinking of natural and synthetic polymers but the mechanical properties of the following hydrogels are relatively low. ${ }^{3}$ Our method of collagen functionalization can act as a basic building block and offers more modularity to incorporate/introduce other ECM functional components (thiol, methacrylate or acrylate derived) e.g. elastin, GAGs or functional peptides in the subsequent crosslinked scaffold to not only tailor the material properties but also to promote specific cell proliferation/encapsulation. The subsequent tailored scaffold might facilitate passive diffusion of cells and growth factors to closely mimic in vivo tissue remodelling. Work is currently underway to assess the matrix modulus influence on encapsulated cell ingrowth, proliferation and differentiation; and the capacity of the hydrogel to absorb and release of bioactive molecules.

\section{Conclusions}

We have demonstrated a modular approach for developing scaffolds that are adapted to their specific desired purposes by integrating functional components through functionalization of collagen with reactive methacrylate groups. The resulting functionalized collagen retained its triple helicity while allowing for increased versatility for further processing. We demonstrated that the functionalized collagen hydrogel could be used both as a cellular substrate as well as a bio-orthogonal 3D cell encapsulation system.

\section{Acknowledgements}

This work was supported by Swedish Research Council Young Investigator Award dnr 621-2012-4286 to JP (support for RR), Treatments of the Future grant dnr 521-2012-5706 to MG. EIA thanks NSERC and UOHI for financial support. We thank Dr. Naresh Polisetti and Dr. C. J. Lee for isolation and characterization of the cardiac progenitors and transfecting the corneal epithelial cells.

\section{Notes and references}

1. N. Annabi, A. Tamayol, J. A. Uquillas, M. Akbari, L. E. Bertassoni, C. Cha, G. Camci-Unal, M. R. Dokmeci, N. A. Peppas and A. Khademhosseini, Advanced materials, 2014, 26, 85-123.

2. X. Jia and K. L. Kiick, Macromolecular bioscience, 2009, 9, 140-156.

3. J. Zhu and R. E. Marchant, Expert review of medical devices, 2011, 8, 607-626.

4. E. Hoch, C. Schuh, T. Hirth, G. M. Tovar and K. Borchers, J Mater Sci: Mater Med, 2012, 23, 2607-2617.

5. Y. T. Lin, C. H. Lin, H. Y. Lu and F. H. Lin, Journal, 2013.

6. P. Georgia, S. Sonja and T. Michael, Synthetic PEG Hydrogels as Extracellular Matrix Mimics for Tissue Engineering Applications, 2012.

7. P. Bajaj, R. M. Schweller, A. Khademhosseini, J. L. West and R. Bashir, Annual Review of Biomedical Engineering, 2014, 16, 247-276.

8. M. K. Nguyen and E. Alsberg, Progress in Polymer Science, 2014, 39, 1235-1265.

9. Y. Tao, X. Tong, Y. Zhang, J. Lai, Y. Huang, Y.-R. Jiang and B.-H. Guo, Acta biomaterialia, 2013, 9, 5022-5030.

10. International Journal of Polymer Science, 2011, 2011.

11. G. Ciardelli, V. Chiono, G. Vozzi, M. Pracella, A. Ahluwalia, N. Barbani, C. Cristallini and P. Giusti, Biomacromolecules, 2005, 6, 1961-1976.

12. O. Buznyk, N. Pasyechnikova, M. M. Islam, S. lakymenko, P. Fagerholm and M. Griffith, Clinical and translational science, 2015, DOI: 10.1111/cts.12293.

13. W. Dai, N. Kawazoe, X. Lin, J. Dong and G. Chen, Biomaterials, 2010, 31, 2141-2152.

14. L. Koh, M. Islam, D. Mitra, C. Noel, K. Merrett, S. Odorcic, P. Fagerholm, W. Jackson, B. Liedberg, J. Phopase and M. Griffith, Journal of functional biomaterials, 2013, 4, 162. 
15. X. Zhang, Y. Yang, J. Yao, Z. Shao and X. Chen, ACS Sustainable Chemistry \& Engineering, 2014, 2, 1318-1324.

16. J. E. McBane, B. Vulesevic, D. T. Padavan, K. A. McEwan, G. S. Korbutt and E. J. Suuronen, PloS one, 2013, 8, e77538.

17. F. Li, D. Carlsson, C. Lohmann, E. Suuronen, S. Vascotto, K. Kobuch, H. Sheardown, R. Munger, M. Nakamura and M. Griffith, Proceedings of the National Academy of Sciences of the United States of America, 2003, 100, 15346-15351.

18. G. Tronci, A. Doyle, S. J. Russell and D. J. Wood, Journal of Materials Chemistry B, 2013, 1, 5478-5488.

19. G. Tronci, S. J. Russell and D. J. Wood, Journal of Materials Chemistry B, 2013, 1, 3705-3715.

20. P. J. O'Brien, A. G. Siraki and N. Shangari, Critical reviews in toxicology, 2005, 35, 609-662.

21. J. S. Miller, C. J. Shen, W. R. Legant, J. D. Baranski, B. L. Blakely and C. S. Chen, Biomaterials, 2010, 31, 3736-3743. K. Xu, Y. Fu, W. Chung, X. Zheng, Y. Cui, I. C. Hsu and W. J. Kao, Acta biomaterialia, 2012, 8, 2504-2516.

23. W. T. Brinkman, K. Nagapudi, B. S. Thomas and E. L. Chaikof, Biomacromolecules, 2003, 4, 890-895.

$24 . \quad$ D.-M. Dragusin, S. Van Vlierberghe, P. Dubruel, M. Dierick L. Van Hoorebeke, H. A. Declercq, M. M. Cornelissen and I.-C. Stancu, Soft Matter, 2012, 8, 9589-9602.

25. L. Moller, A. Krause, J. Dahlmann, I. Gruh, A. Kirschning and G. Drager, The International journal of artificial organs, 2011, 34, 93-102.

26. A. Fathi, S. M. Mithieux, H. Wei, W. Chrzanowski, P. Valtchev, A. S. Weiss and F. Dehghani, Biomaterials, 2014, 35, 5425-5435.

27. S.-H. Kim and C.-C. Chu, Journal of Biomedical Materials Research, 2000, 49, 517-527.

28. I. D. Gaudet and D. I. Shreiber, Biointerphases, 2012, 7.

29. H. Tan, H. Luan, Y. Hu and X. Hu, Macromol. Res., 2013, 21, 392-399.

30. M. D. Shoulders and R. T. Raines, Annual review of biochemistry, 2009, 78, 929-958.

31. C.-Y. Liu, M. Matsusaki and M. Akashi, Polym J, 2015, 47, 391-399.

32. H. Cheng, S. Rashid, Z. Yu, A. Yoshizumi, E. Hwang and B. Brodsky, The Journal of biological chemistry, 2011, 286, 2041-2046.

33. X. Liu, W. Dan, H. Ju, N. Dan and J. Gong, RSC Advances, 2015, 5, 52079-52087.
34.

L.-T. T. Nguyen, M. T. Gokmen and F. E. Du Prez, Polymer Chemistry, 2013, 4, 5527-5536.

35. J. W. Chan, C. E. Hoyle, A. B. Lowe and M. Bowman, Macromolecules, 2010, 43, 6381-6388.

36. G. D. Nicodemus and S. J. Bryant, Tissue Eng Part B Rev, 2008, 14, 149-165.

37. J. L. S. Lopes, A. J. Miles, L. Whitmore and B. A. Wallace, Protein Science, 2014, 23, 1765-1772.

38. J. L. Vanderhooft, M. Alcoutlabi, J. J. Magda and G. D. Prestwich, Macromolecular Bioscience, 2009, 9, 20-28.

39. P. B. Welzel, S. Prokoph, A. Zieris, M. Grimmer, S. Zschoche, U. Freudenberg and C. Werner, Polymers, 2011, 3, 602.

40. Y. Yu, C. Deng, F. Meng, Q. Shi, J. Feijen and Z. Zhong, Journal of biomedical materials research. Part A, 2011, 99, 316-326.

41. M. Achilli and D. Mantovani, Polymers, 2010, 2, 664.

42. H. Tan, A. DeFail, J. P. Rubin, C. R. Chu and K. G. Marra, Journal of biomedical materials research. Part A, 2010, 92, 979-987.

43. F. J. O'Brien, Materials Today, 2011, 14, 88-95.

44. M. L. Oyen, Int Mater Rev, 2014, 59, 44-59.

45. Y. X. Zhan and X. R. Niu, Bioinspir Biomim Nan, 2015, 4, 140-154.

46. J. Zhu, P. He, L. Lin, D. R. Jones and R. E. Marchant, Biomacromolecules, 2012, 13, 706-713.

47. G. M. Cruise, D. S. Scharp and J. A. Hubbell, Biomaterials, 1998, 19, 1287-1294.

48. J. L. Young and A. J. Engler, Biomaterials, 2011, 32, 10021009.

49. K. Xu, D. A. Cantu, Y. Fu, J. Kim, X. Zheng, P. Hematti and W. J. Kao, Acta biomaterialia, 2013, 9, 8802-8814.

50. Y. Jiang, J. Chen, C. Deng, E. J. Suuronen and Z. Zhong, Biomaterials, 2014, 35, 4969-4985.

51. M. Guvendiren and J. A. Burdick, Nat Commun, 2012, 3, 792.

52. R. Ravichandran, M. Griffith and J. Phopase, Journal of Materials Chemistry B, 2014, 2, 8466-8478.

53. E. Cosgriff-Hernandez, M. S. Hahn, B. Russell, T. Wilems, D. Munoz-Pinto, M. B. Browning, J. Rivera and M. Höök, Acta biomaterialia, 2010, 6, 3969-3977.

54. L. Cai and S. C. Heilshorn, Acta biomaterialia, 2014, 10, 1751-1760. 


\section{Cover Picture}

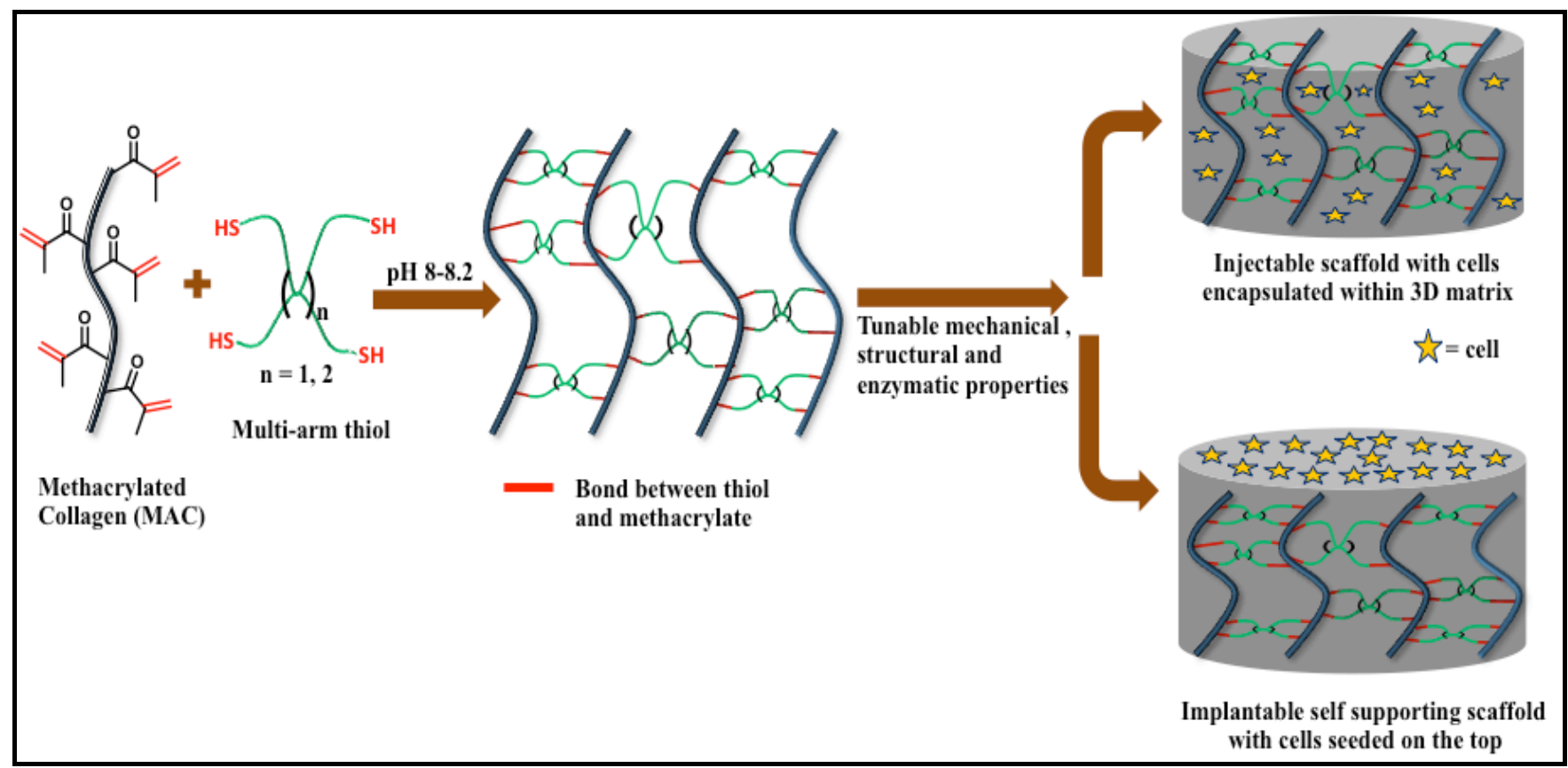

Modulating the hydrogel properties from injectable to implantable scaffolds using bio-orthogonal thiol-Michael Addition click reaction. 


\section{Supplementary Information}

Functionalised type-I collagen as hydrogel building blocks for bio-orthogonal tissue engineering applications.

R. Ravichandran, ${ }^{\mathrm{a}, \S}$ M.M. Islam, ${ }^{\mathrm{b}, \S}$ E. I. Alarcon, ${ }^{\mathrm{c}}$ A. Samanta, ${ }^{\mathrm{d}}$ S. Wang, ${ }^{\mathrm{e}}$ P. Lundström, ${ }^{\mathrm{f}}$ J. Hilborn, ${ }^{\mathrm{e}}$ M. Griffith, ${ }^{\mathrm{d}^{*}}$ and J. Phopase ${ }^{\mathrm{a}^{*}, \dagger}$ 


\section{Table of contents}

1. Materials ............................................................ 3

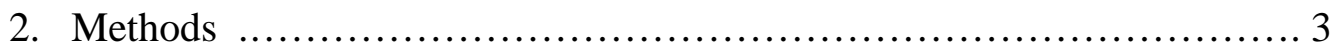

2.1 Synthesis of methacrylated collagen $\ldots \ldots \ldots \ldots \ldots \ldots \ldots \ldots \ldots \ldots \ldots$

2.2 Trinitrobenzene sulfonic acid (TNBS) assay $\ldots \ldots \ldots \ldots \ldots \ldots \ldots \ldots . \ldots \ldots$

2.3 Nuclear Magnetic Resonance (NMR) .............................4

2.4 Circular Dichroism ............................................... 4

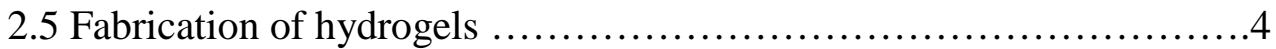

2.6 Determination of sol-gel fraction ................................... 5

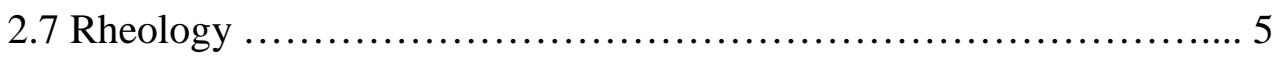

2.8 Collagenase assay........................................... 6

2.9 Cryo-Scanning Electron Microscopy (SEM) .........................

2.10 In vitro biocompatability of human corneal epithelial cells

(HCEC)........ 7

$2.113-\mathrm{D}$ in vitro cardiac stem cell (CSC) encapsulation in hydrogel

matrix .... 7

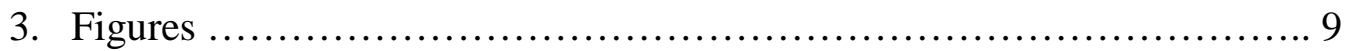

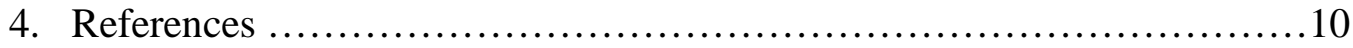




\section{Experimental section}

\section{Materials}

Freeze dried porcine collagen was purchased from NIPPON meat packers, Japan, sodium hydroxide, triethanolamine, methacrylic anhydride, $N$-ethyl- $N$ '-(3-dimethylaminopropyl) carbodiimide hydrochloride (EDC), $N$-hydroxysuccinimide (NHS) were purchased from Sigma-Aldrich, St.Louis, USA. Acrylic anhydride was purchased from abcr GmbH Germany, 8 arm thiol [Poly ethylene glycol (tri-pentaerythritol)] and 4 arm thiol [Poly Ethylene Glycol (pentaerythritol)] molecular weight 10,000 Da were purchased from JenKem Technology, USA. Rat-tail collagen type-I was purchased from BD biosciences, UK.

\section{Methods}

\subsection{Synthesis of methacrylated collagen}

Freeze dried collagen was dissolved in Milli Q water and gently stirred. The $\mathrm{pH}$ of collagen solution was increased to $\mathrm{pH} 10$ using $2 \mathrm{~N} \mathrm{NaOH}$ and methacrylic anhydride at a molar ratio of 5:1 (with respect to number of lysine amine groups in collagen) was added subsequently drop-wise at room temperature to modify the pristine collagen with reactive functional groups (Scheme 1). The reaction mixture was dialyzed against distilled water (pH 10) using 12-14kDa cutoff dialysis tubing (Spectrum Laboratories, Inc., CA, US) for 2-3 days to remove reaction by-products and lyophilized for 3-4 days to and stored at $4^{\circ} \mathrm{C}$ until further use.

\subsection{Tri-nitro benzene sulfonic acid (TNBS) assay}

The extent of modification of MAC and AC was quantified using TNBS (2,4,6-trinitrobenzenesulfonic acid) calorimetric assay, by previously established protocols. ${ }^{1,2}$ Briefly, $2 \mathrm{mg}$ of dry sample was mixed with $1 \mathrm{ml}$ of $4 \mathrm{wt} \% \mathrm{NaHCO} 3\left(\mathrm{pH} 8.5\right.$ ) and $1 \mathrm{ml}$ of $0.5 \mathrm{wt} \%$ TNBS solution at $40^{\circ} \mathrm{C}$ under mild shaking. After 4 hours of reaction, $3 \mathrm{~mL}$ of $6 \mathrm{M} \mathrm{HCl}$ solution was added and the mixture was heated to $90^{\circ} \mathrm{C}$ to dissolve any sample residuals. Then the solutions were cooled and extracted three times with anhydrous diethyl ether to remove the unreacted TNBS species. UV absorbance of samples was recorded using Shimadzu UV-Vis spectrophotometer (UV-2450) against a blank, prepared by the above procedure, except that the $\mathrm{HCl}$ solution was added before the addition of TNBS. The content of free amino acid groups and degree of functionalization (F) were calculated as follows:

$$
\frac{\text { moles }(\text { Lys })}{g(\text { collagen })}=\frac{2 \cdot A b s_{346} \cdot 0.02}{1.46 \cdot 10^{4} \cdot b \cdot x}
$$




$$
F=1-\frac{\text { moles }(\text { Lys }) \text { modified collagen }}{\text { moles }(\text { Lys }) \text { pristine collagen }}
$$

where Abs $\left({ }_{346}\right)$ is the absorbance value at $346 \mathrm{~nm}, 1.4 \times 10^{4}$ is the molar absorption coefficient for 2, 4 , 6-trinitrophenyl lysine $\left(\mathrm{l}_{\mathrm{mol}}^{-1} \cdot \mathrm{cm}^{-1}\right), b$ is the cell path length $(1 \mathrm{~cm}), x$ is the sample weight and moles (Lys) modified collagen and moles (Lys) collagen represent the lysine molar content in functionalized and pristine collagen, respectively.

\subsection{Nuclear Magnetic Resonance}

Structural properties and the degree of methacrylation of collagen lysine amines of collagen were also analyzed by ${ }^{1} \mathrm{H}$ NMR spectroscopy, using a $500 \mathrm{MHz}$ Varian Inova NMR spectrometer equipped with a cryoprobe. Briefly, $3 \mathrm{mg}$ MAC and pristine collagen was dissolved in $3 \mathrm{ml}$ of deuterium oxide. Sodium 3-(trimethylsilyl)-2,2',3,3'-tetradeuteropropionic acid was added to reference chemical shifts. In order to remove air bubbles, the dissolved samples were centrifuged at $1700 \mathrm{rpm}, 20^{\circ} \mathrm{C}$ for $10 \mathrm{~min}$. The degree of modification of collagen lysine amines was quantified from a protocol defined by earlier methods ${ }^{3}$. The ${ }^{1} \mathrm{H}$ NMR spectra were normalized to signals of phenylalanine sidechains (6.9-7.5 ppm) to obtain to collagen concentrations. Subsequently, the lysine methylene signals (2.8-2.95 ppm) of pristine collagen and MAC were integrated to determine the degree of functionalization using,

$$
F=\left(1-\frac{\mathrm{A}(\text { Lysine methylene of MAC })}{\mathrm{A}(\text { Lysine methylene of pristine collagen })}\right) \times 100 \%
$$

where A(lysine methylene of MAC) and A(lysine methylene of pristine collagen) are the integrated intensities corresponding to functionalized and pristine collagen, respectively.

\subsection{Circular Dichroism}

All spectra were performed on a Chirascan ${ }^{\mathrm{TM}}$ CD Spectrometer, Applied Photophysics Ltd., (Surrey, UK). Briefly, a quartz cell of $0.1 \mathrm{~cm}$ path length was used to record the CD spectra's of collagen and modified collagen samples between $180-260 \mathrm{~nm}$ at a scan rate of $1 \mathrm{~nm} / \mathrm{s}$. A spectrum of double distilled water was subtracted from collagen and modified collagen spectra. Rpn (Ratio of positive to negative band) was calculated from the resulting spectra for collagen before and after modification.

\subsection{Fabrication of hydrogels and sol-gel characterization}

A T-piece syringe mixing system established in our lab was used to fabricate the hydrogels (16). Briefly, 500mg ( $\mathrm{pH}$ 6.7-7) of methacrylated collagen (MAC) 10\% (w/w) was taken in glass syringe 
and mixed with multi-arm PEG thiols (4arm and 8arm) at different functional ratios to fabricate hydrogels. Multi-arm PEG thiols were dissolved in deoxygenated water before its use. Three different formulations of MAC and 4 arm PEG thiols (4A) at functional ratios 1:0.5(1); 1:1(2) and 1:2(3) with the increasing functional equivalents of thiols to MAC, denoted as M4A1, M4A2 and M4A3 respectively to form discrete gels. Similarly four different formulations of MAC and 8 arm PEG thiols (8A) at functional ratios 1:0.5(1); 1:1(2); 1:2(3) and 1:4(4) with the increasing functional equivalents of thiols to MAC, denoted as M8A1, M8A2, M8A3 and M8A4 respectively to from discrete gels. In order to improve the gelation time of hydrogels, $0.05 \mathrm{M}$ TEOA was added before addition of thiols in the syringe system to increase the $\mathrm{pH}$ to 8-8.2 of the final formulation. All the reaction mixture in the syringe was mixed between 25-30 cycles in order to fabricate homogenous hydrogels.

\subsection{Determination of sol-gel fraction}

To characterize the sol-gel fraction, all the fabricated hydrogels were cut into pieces $(n=3)$ and dried. The dried weights $\left(\mathrm{W}_{\mathrm{o}}\right)$ were obtained gravimetrically and incubated in ddH2O on an orbital shaker for 24hr to remove the sol fraction. Further the gels were dried again under vacuum to obtain constant weight (Wt). The gel fraction was calculated using the following equation 4 and 5., 5

$$
\begin{aligned}
& \text { Sol fraction }(\%)=\left[\frac{W o-W t}{W o}\right] \times 100 \\
& \text { Gel fraction }(\%)=100-\text { sol fraction }
\end{aligned}
$$

\subsection{Rheology}

Mechanical properties of hydrogels were assessed using parallel plate rheometry (AR 2000 rheometer, TA instruments, Inc., UK). Fabricated hydrogels were punched in cylindrical shape (1mm thick, 10mm diameter) and bulk modulus (G') and viscous modulus (G’’) measurements were recorded at a frequency range of $1-10 \mathrm{~Hz}$ at $25^{\circ} \mathrm{C}$ using $8 \mathrm{~mm}$ aluminum plate geometry. The gap was adjusted starting from the original sample height and compressing the sample to reach the sample reach a normal force of $0.3 \mathrm{~N}$. Rheological measurements were made on hydrogels after $24 \mathrm{~h}$ post gelation. The storage modulus $\left(\mathrm{G}^{\prime}\right)$ values from the frequency dependent measurement were used to determine the $\xi$ (Mesh size) and Mc (average molecular weight between crosslinks) using equation 6 and 7 respectively. ${ }^{6}$

$$
\xi=\left(\frac{G^{\prime} N A}{\mathrm{RT}}\right)^{-1 / 3}
$$




$$
\mathrm{Mc}=\frac{\mathrm{C} \rho \mathrm{RT}}{\mathrm{G}^{\prime} \mathrm{p}}
$$

where $\mathrm{C}$ is the final polymer concentration $(5 \% \mathrm{w} / \mathrm{v}), \quad \rho$ is the density of water at $298 \mathrm{~K}(997 \mathrm{~kg}$ $\mathrm{m}^{-3}$ ), $\mathrm{R}$ is the molar gas constant, $\mathrm{G}^{\prime} \mathrm{p}$ is the peak value of $\mathrm{G}^{\prime}, \mathrm{NA}$ is the Avogadro constant and $\mathrm{T}$ is temperature $(298 \mathrm{~K})$.

In situ gel kinetics was also measured using AR2000 Advanced Rheometer (TA Instruments) with a custom made parallel plate titanium geometry of $19 \mathrm{~mm}$ diameter was used for the rheological characterization of the hydrogels as described earlier. ${ }^{7}$ Gel components, methacrylated collagen and PEG thiols (M4A2 and M8A3) were pre-mixed as described in earlier section. The formulations without any TEOA catalyst will be denoted as M4A2.1 and M8A3.1 respectively. A total volume of 1 $\mathrm{mL}$ of the resulting material was injected into a custom-made cylindrical aluminum plate as described by authors. Acrylated collagen (AC) was synthesized using the same method like MAC synthesis using acrylic anhydride as a reactant. It was mixed with multi-arm PEG thiols $4 \mathrm{~A}$ and $8 \mathrm{~A}$ to from A4A2 and A8A3 gels. Similarly, the formulations without any TEOA catalyst will be donated as A4A2.1 and A8A3.1 respectively. Oscillatory stress sweeps were performed on hydrogels shortly after mixing and thereafter at different time intervals over $10 \mathrm{~h}$ to monitor the curing process. The first measurement was recorded 15 min after mixing and the normal force $(0.3 \mathrm{~N})$, temperature $\left(25^{\circ} \mathrm{C}\right)$, and frequency $(0.1 \mathrm{~Hz})$ was kept constant. The samples were covered with Parafilm $\mathrm{M}$ and kept in moist condition between measurements. The rates of gelation at different time intervals were compared via the normalized elastic modulus, $G_{r}^{\prime}=\left[G^{\prime}(t)-G_{0}^{\prime}\right] /\left[G_{\infty}^{\prime}-G_{0}^{\prime}\right]$, where $G_{0}^{\prime}$ is the elastic modulus at the starting point and $\mathrm{G}_{\infty}^{\prime}$ is the equilibrium elastic modulus after complete gelation. $\mathrm{G}_{\infty}^{\prime}$ is the average of the last $10 \mathrm{G}^{\prime}$ points obtained from frequency sweep measurements. ${ }^{8}$

\subsection{Collagenase assay}

Enzymatic degradation of hydrogels was done using Type-I-Collagenase from Clostridium histolyticum (Sigma-Aldrich, St.Louis, USA). Hydrogels resulted from formulations M8T3 and M8T4 were used in this study along with native collagen (5\%) cross-linked with EDC-NHS serving as control. The control samples were fabricated according to the protocol mentioned earlier. ${ }^{9}$ Hydrogels of $1 \mathrm{~mm}$ thickness were cut into small pieces of $6 \mathrm{~mm}$ diameter were placed in a vial containing $5 \mathrm{U} / \mathrm{mL}$ collagenase solution in $0.1 \mathrm{M}$ tris-HCL $(\mathrm{pH} 7.4)$ and $5 \mathrm{mM} \mathrm{CaCl}_{2}$. Further the samples were incubated at $37^{\circ} \mathrm{C}$ and the collagenase solution was changed at every 8 hours and the sample weights were 
measured at different time points. Enzymatic degradation of samples relative to their original weight were measured as function of time using the following equation where Wo is the original or initial weight of sample and $\mathrm{Wt}$ is the weight of degraded sample at certain intervals. ${ }^{9}$

$$
\text { Residual mass }=\frac{W t}{W o} \times 100 \%
$$

\subsection{Cryo-Scanning electron microscopy (SEM)}

Low temperature scanning electron microscopy (Cryo-SEM) was carried out in a Tescan (Vega II $\mathrm{XMU}$ ) with cold stage sample holder at $-50^{\circ} \mathrm{C}$ using a backscattered electron detector (BSE) and secondary electron detector (SED). A $6 \mathrm{~mm}$ circular piece of the M8T4 hydrogel formulation was blotted and sectioned prior imaging. The images shown correspond to representative cross sections of the material. In all cases fast speed scanning was used and no sample burning was observed.

\subsection{In vitro biocompatibility of human corneal epithelial cells (HCEC)}

Green fluorescence protein (GFP) transfected HCECs were seeded on pre-polymerized top of the hydrogel surface to evaluate the biocompatibility of the material. A stable GFP-HCEC cell line was established by the method earlier. ${ }^{10}$ The fabricated M8T4 hydrogels were cut into $6 \mathrm{~mm}$ hydrogel discs and fitted into 96 well plates followed by sterilization with 3X antibiotic solution consisting of 300 $\mathrm{U} / \mathrm{ml}$ penicillin and $300 \mu \mathrm{g} / \mathrm{mL}$ streptomycin. Proliferation of HECEs on hydrogel surface was evaluated by seeding five thousand cells on top of the hydrogel. Cells were also seeded on tissue culture plate and pristine collagen cross-linked with EDC-NHS ${ }^{9}$ were serving as positive control along with an hydrogel made from 8 arm PEG thiol cross-linked with 8 arm PEG maleimide (Mn= 41600, Creative PEGWorks, NC, US) serving as negative control. The seeded cells were maintained in Keratinocyte-serum free media (KSFM; Life Technologies, Invitrogen, Paisley, UK containing $50 \mu \mathrm{g} / \mathrm{mL}$ bovine pituitary extract and $5 \mathrm{ng} / \mathrm{ml}$ epidermal growth factor) within a humidified $37^{\circ} \mathrm{C}$ incubator with 5\% CO2. Photomicrographs of the cells were taken at Day 1,3 and 5 using a fluorescence microscope (AxioVert A1, Carl Zeiss, Göttingen, Germany). Three different areas of $1290 \times 965 \mu \mathrm{m}^{2}$ each were sampled for cell counts.

\subsection{3-D in vitro cardiac progenitor cell encapsulation in hydrogel matrix}

Murine cardiac progenitor cells (CPCs) were isolated from 3-week-old C57BL/6 mouse hearts using a Millipore Cardiac Stem Cell Isolation kit (Millipore, Darmstadt, Germany), following the manufacturer's protocol and with prior ethical approval from the Djurförsöksetiska Nämnden Linköping (Animal Ethical Committee, Linköping). They were cultured and maintained in DMEM/ 
F12 + GlutaMAX ${ }^{\mathrm{TM}}$-I (1X ) media containing 10\% FCS, 1\% PEST, 1X ITS (Insulin, Transferrin, Selinium), 0.5\% DMSO and EGF (20ng/mL). For encapsulation, $1 \times 10^{6}$ cells were mixed inside $1 \mathrm{ml}$ of M8T4 hydrogel matrix ( $\mathrm{n}=3$ samples). Unmodified type I rat tail collagen that had been neutralized with HEPES buffer and $1 \mathrm{~N} \mathrm{NaOH}$ to $\mathrm{pH} 7.0$ and into which CPCs were mixed and then thermogelled at $37^{\circ} \mathrm{C}$ served as controls $(n=3) .{ }^{11,12}$ Both sets of encapsulated cells were maintained in a humidified, $37^{\circ} \mathrm{C}$ incubator with $5 \% \mathrm{CO}_{2}$ and supplemented with culture media. On day 3 of culture, the composite cell-hydrogel matrices were harvested, washed with $1 \mathrm{X}$ sterile PBS and incubated at $37^{\circ} \mathrm{C}$ with calcein AM/ethidium homodimer (4/2 $\mu \mathrm{M}$, Live Dead, Invitrogen, Grand Island NY) for 20-30 min to evaluate cell viability. The stained constructs were imaged using confocal microscope (LSM700, Carl Zeiss, Germany). 3-D stacking and Z-sectioning was also performed using LSM700 software to assess the infiltration of cells on the hydrogel matrix. 


\section{Figures}
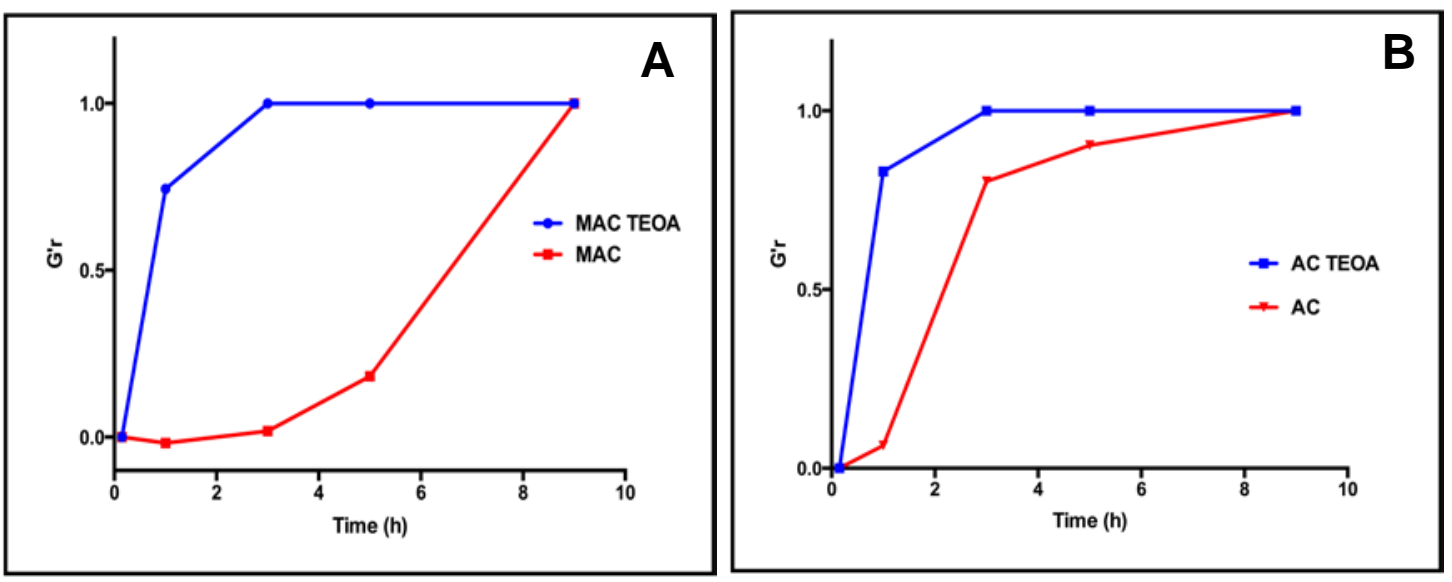

Figure S1. In situ gelation kinetic graphs of 4 arm PEG thiol cross-linked with (A) MAC with and without TEOA (M4A2 and M4A2.1 formulations) and (B) AC with and without TEOA (A4A2 and A4A2.1) formulations. 


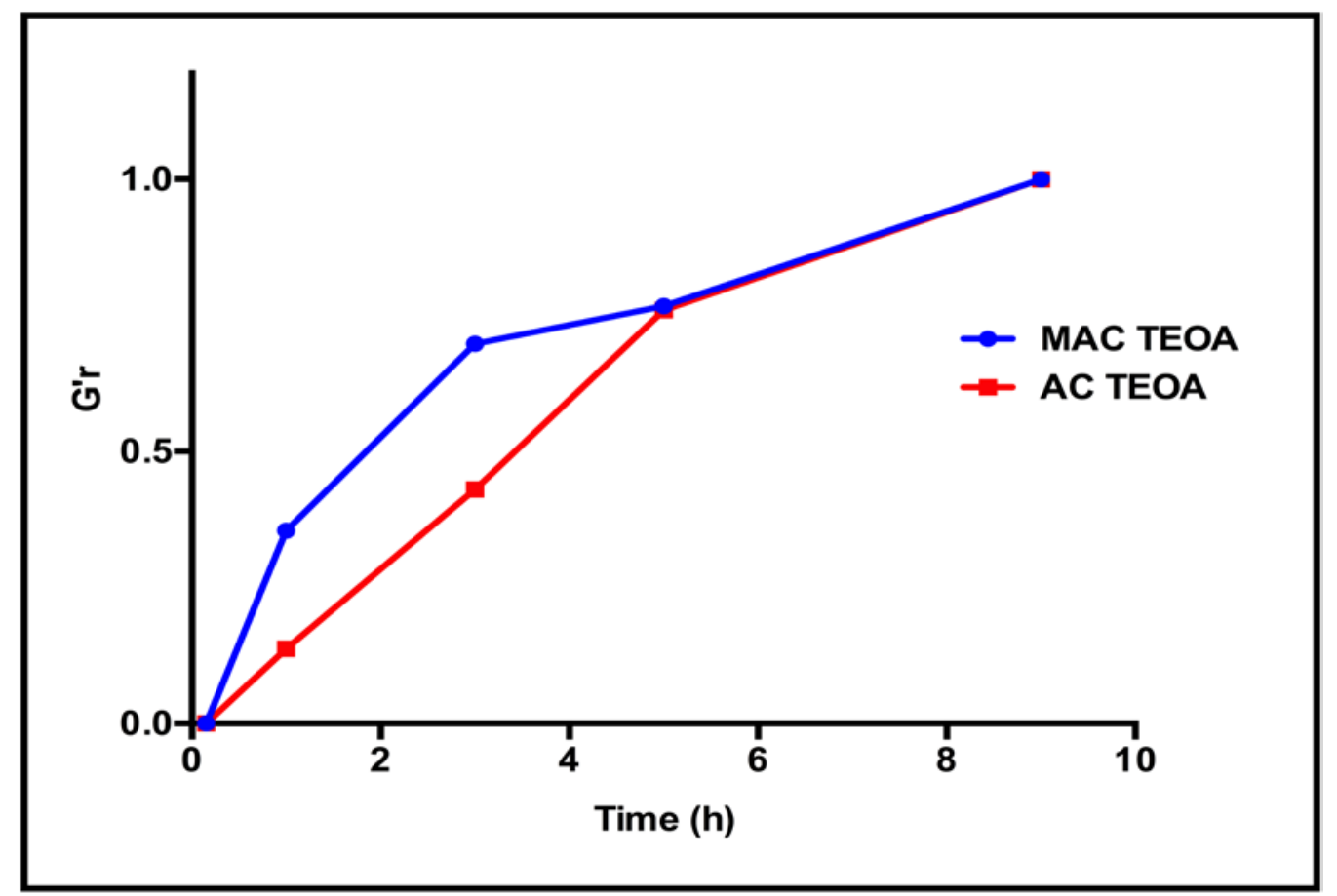

Figure S2: In situ gelation kinetic graph of 8 arm PEG thiol cross-linked with MAC and AC with TEOA (M8A3 and A8A3 formulations).

\section{References}

1. G. Tronci, A. Doyle, S. J. Russell and D. J. Wood, Journal of Materials Chemistry B, 2013, 1, 5478-5488.

2. G. Tronci, S. J. Russell and D. J. Wood, Journal of Materials Chemistry B, 2013, 1, 3705-3715.

3. E. Hoch, C. Schuh, T. Hirth, G. M. Tovar and K. Borchers, J Mater Sci: Mater Med, 2012, 23, 2607-2617.

4. M. Hanif, N. M. Ranjha, M. H. Shoaib, J. Mudasser, R. I. Yousuf, A. Khan and M. Zia-Ul-Haq, Pak J Pharm Sci, 2011, 24, 503-511.

5. $\quad$ C. C. Lin, A. Raza and H. Shih, Biomaterials, 2011, 32, 9685-9695.

6. O. P. Oommen, S. Wang, M. Kisiel, M. Sloff, J. Hilborn and O. P. Varghese, Advanced Functional Materials, 2013, 23, 1273-1280.

7. S. Piskounova, R. Rojas, K. Bergman and J. Hilborn, Macromolecular Materials and Engineering, 2011, 296, 944-951.

8. Y.-l. Yang and L. J. Kaufman, Biophysical journal, 2009, 96, 1566-1585. 
9. L. B. Koh, M. M. Islam, D. Mitra, C. W. Noel, K. Merrett, S. Odorcic, P. Fagerholm, W. B. Jackson, B. Liedberg, J. Phopase and M. Griffith, Journal of functional biomaterials, 2013, 4, 162-177.

10. M. Mirazul Islam, V. Cepla, C. He, J. Edin, T. Rakickas, K. Kobuch, Z. Ruzele, W. B. Jackson, M. Rafat, C. P. Lohmann, R. Valiokas and M. Griffith, Acta biomaterialia, 2015, 12, 70-80.

11. R. Hartwell, V. Leung, C. Chavez-Munoz, L. Nabai, H. Yang, F. Ko and A. Ghahary, Acta biomaterialia, 2011, 7, 3060-3069.

12. K. Xu, D. A. Cantu, Y. Fu, J. Kim, X. Zheng, P. Hematti and W. J. Kao, Acta biomaterialia, 2013, 9, 8802-8814. 